ORIGINAL ARTICLE

\title{
Randomised controlled comparison of continuous positive airways pressure, bilevel non-invasive ventilation, and standard treatment in emergency department patients with acute cardiogenic pulmonary oedema
}

\author{
S D Crane, M W Elliott, P Gilligan, K Richards, A J Gray
}

Emerg Med J 2004;21:155-161. doi: 10.1136/emj.2003.005413

See end of article for authors' affiliations

Correspondence to:

Dr S D Crane, Department of Emergency Medicine, York Hospital, Wigginton Road, York YO31 8HE UK; seven.crane@ york.nhs.uk

Accepted for publication 20 March 2003

\begin{abstract}
Background: Continuous positive airways pressure (CPAP) and bilevel non-invasive ventilation may have beneficial effects in the treatment of patients with acute cardiogenic pulmonary oedema. The efficacy of both treatments was assessed in the UK emergency department setting, in a randomised comparison with standard oxygen therapy.

Methods: Sixty patients presenting with acidotic $(\mathrm{pH}<7.35)$ acute, cardiogenic pulmonary oedema, were randomly assigned conventional oxygen therapy, CPAP $\left(10 \mathrm{~cm} \mathrm{H}_{2} \mathrm{O}\right)$, or bilevel ventilation (IPAP $15 \mathrm{~cm} \mathrm{H}_{2} \mathrm{O}$, EPAP $5 \mathrm{~cm} \mathrm{H}$ O) provided by a standard ventilator through a face mask. The main end points were treatment success at two hours and in-hospital mortality. Analyses were by intention to treat. Results: Treatment success (defined as all of respiratory rate $<23 \mathrm{bpm}$, oxygen saturation of $>90 \%$, and arterial blood $\mathrm{pH}>7.35$ (that is, reversal of acidosis), at the end of the two hour study period) occurred in three (15\%) patients in the control group, seven (35\%) in the CPAP group, and nine (45\%) in the bilevel group $(p=0.116)$. Fourteen (70\%) of the control group patients survived to hospital discharge, compared with $20(100 \%)$ in the CPAP group and $15(75 \%)$ in the bilevel group ( $p=0.029$; Fisher's test).

Conclusions: In this study, patients presenting with acute cardiogenic pulmonary oedema and acidosis, were more likely to survive to hospital discharge if treated with CPAP, rather than with bilevel ventilation or with conventional oxygen therapy. There was no relation between in hospital survival and early physiological changes. Survival rates were similar to other studies despite a low rate of endotracheal intubation.
\end{abstract}

\begin{abstract}
$\Lambda$ cute cardiogenic pulmonary oedema (CPO) is a common cause of acute respiratory failure, presenting to emergency departments. Non-invasive ventilation has been shown to improve oxygenation, increase cardiac output, and reduce the work of breathing. ${ }^{1-4}$ Several studies have evaluated the use of continuous positive airway pressure (CPAP) in acute $\mathrm{CPO},{ }^{5-13}$ and others have evaluated the use of bilevel positive airway pressure. ${ }^{13-16}$ Collectively, the available data suggest that CPAP is effective in terms of reduction in intubation rate and that there is a trend towards reduced mortality.$^{17}$ In the UK intubation rates for patients presenting to emergency departments are low (10.5\% of all patients with acidotic CPO in one study ${ }^{18}$ ) and it therefore remains to be seen whether CPAP has a role in UK practice. Studies evaluating bilevel ventilation have variable conclusions, some appearing to show significant benefits, ${ }^{15}$ while others suggest significant disadvantages with this modality. ${ }^{13}{ }^{14}$ One study compared both types of non-invasive ventilation with standard treatment, concluded that bilevel ventilation significantly reduced intubation rate compared with CPAP and controls in patients with CPO. ${ }^{19}$ These studies are all quite small and have largely been performed in intensive care areas with the help of invasive monitoring.

Emergency departments in the UK have increasingly used non-invasive ventilators within resuscitation areas, for the treatment of patients with acute respiratory failure secondary to chronic obstructive pulmonary disease (COPD) and $\mathrm{CPO}^{20}{ }^{21}$ Such use is often aimed at stabilisation before transfer to a ward or prevention of endotracheal intubation, with all its inherent complications and costs.
\end{abstract}

We therefore, undertook a prospective randomised controlled trial to investigate whether either CPAP or bilevel ventilation would result in faster recovery within the emergency department in the UK setting, as compared with the use of standard oxygen treatment, in patients with acute CPO. Furthermore, we wished to establish whether, in view of low intubation rates in the UK, this would translate into an improved survival.

\section{METHODS}

\section{Patients}

Adults who attended either of the emergency department resuscitation rooms of two university hospitals in Leeds with acute dyspnoea, and who had clinical evidence of CPO in the opinion of the treating doctor (for example, widespread pulmonary crepitations, diaphoresis) were eligible for enrolment. Inclusion criteria were: respiratory rate greater than 23 breaths per minute, chest radiological appearance consistent with pulmonary oedema, and arterial blood $\mathrm{pH}<7.35\left(\mathrm{H}^{+}\right.$ion concentration $>46.7 \mathrm{nmol} / \mathrm{l})$. Exclusion criteria were: hypotension (systolic blood pressure $<90 \mathrm{~mm} \mathrm{Hg}$ ), temperature $>38^{\circ} \mathrm{C}$, patients requiring immediate thrombolysis for myocardial infarction, patients requiring dialysis for renal impairment,

\footnotetext{
Abbreviations: CPO, cardiogenic pulmonary oedema; CPAP, continuous positive airway pressure; COPD, chronic obstructive pulmonary disease
} 
patients with impaired consciousness (only responding to pain or not responding at all), and patients with dementia.

All patients were initially given standard oxygen at a rate of 10 litres per minute via non-rebreathe face mask and medical therapy (that is, frusemide, nitrates, and diamorphine) as determined by medical staff without restriction on dose or route of administration. Standard treatments given throughout the study period were recorded and compared for the three groups. One of three researchers (SC, PG, or KR) was phoned on arrival of the patient and was then responsible for patient care during the rest of the study period.

The research ethics committee of the Leeds Teaching Hospitals NHS Trust approved the study. All the patients in the study, or their next of kin, gave informed consent to participate. This was written in the majority of cases; in 17 cases verbal informed consent was obtained from the patient and witnessed by another member of the emergency department staff.

\section{Design}

Twenty patients each were randomly assigned to standard face mask oxygen, CPAP, or bilevel ventilation. The randomisation sequence was generated using random numbers produced by Microsoft Excel. Assignments were concealed in an opaque envelope, which was then further concealed within another. Once enrolled within the study it was impossible to mask treatment allocation. We aimed to enrol 60 consecutive eligible patients.

A specialist registrar in emergency medicine and an emergency department nurse managed all patients for a two hour period after application of the study treatment. The study treatment was applied for the whole two hour period except when it was not tolerated by the patient. All patients were managed within the resuscitation room of the emergency department. In all three groups the aim was to maintain oxygen saturation above $90 \%$ by changing oxygen flow rates as required. Further doses of frusemide, nitrates, or diamorphine could be given, without restriction, in response to the clinical condition of the patient. Patients were monitored with pulse oximetry, non-invasive blood pressure recordings, and electrocardiography. Respiratory rate was measured by observation over one minute periods. These physiological data were recorded every 10 minutes. Total urine output from arrival to the end of the study period was recorded. A $10 \mathrm{~cm}$, unmarked, visual analogue scale of breathlessness (ranging from "not at all breathless" to "the worst breathlessness imaginable to me") was used to assess the patients' perception of dyspnoea at the start of the study and at 30 minute intervals over the two hour period. Arterial blood samples were drawn at baseline, one, and two hours and analysed for $\mathrm{pH}, \mathrm{pO}_{2}$, and $\mathrm{pCO}_{2}$. Twelve lead electrocardiographs were recorded at baseline, one, and two hours to monitor for the development of acute myocardial infarction.

Patients assigned to either of the non-invasive ventilation arms received positive airway pressure via a full face mask, connected to a VPAP II ventilator (ResMed, Abingdon, UK). In the CPAP group a continuous pressure of $10 \mathrm{~cm} \mathrm{H}_{2} \mathrm{O}$ was generated. All patients in the bilevel group received IPAP of $15 \mathrm{~cm} \mathrm{H}_{2} \mathrm{O}$ and EPAP of $5 \mathrm{~cm} \mathrm{H}_{2} \mathrm{O}$. These levels were chosen to provide a mean pressure of $10 \mathrm{~cm} \mathrm{H}_{2} \mathrm{O}$ in both the treatment arms. Adjustments were not made to these pressures.

Treatment failure was defined, a priori, as worsening clinical signs (either respiratory rate greater than $40 \mathrm{bpm}$ or less than $10 \mathrm{bpm}$, or reducing consciousness level as determined by the AVPU scale) associated with a falling arterial $\mathrm{pH}$ (less than on arrival and less than 7.2). These patients were considered for endotracheal intubation and mechanical ventilation.

Treatment success was defined, a priori, as all of respiratory rate less than $23 \mathrm{bpm}$, oxygen saturation of greater than $90 \%$ and arterial blood $\mathrm{pH}$ greater than 7.35 (that is, reversal of acidosis), at the end of the two hour study period.

In those who were unable to tolerate non-invasive ventilation, it was stopped and standard face mask oxygen applied. Such patients had continued observations and data were analysed according to original treatment assignment (that is, by intention to treat).

After the two hour study period in the emergency department the patients were transferred to another ward within the hospital. Patients were followed up until hospital discharge or death. The diagnosis of myocardial infarction was made if, during the three days after their admission, the patients developed ECG changes or a creatine kinase rise consistent with that diagnosis (defined a priori as greater than double the upper limit of normal (140 IU/l) as defined by our laboratory - that is, $>280 \mathrm{IU} / \mathrm{l}$ ).

Eligible patients who were not randomised were identified by weekly scrutiny of the resuscitation room records. Baseline demographic and physiological data were recorded from these patients' notes to permit a comparison with those randomised.

\section{Statistical analysis}

Physiological measurements after intubation were excluded from the analysis. SPSS v9 for Windows was used to conduct the analysis. Analysis of variance, with the Bonferroni test for repeated comparisons, was used to compare physiological parameters in the three groups at each time point. Variables without normal distribution and homogeneous variance were analysed with the Kruskal-Wallis test. Student's paired $t$ tests were used to compare variables within groups over time. The $\chi^{2}$ test or Fisher's exact test, where appropriate, were used to compare categorical variables. We performed univariate analysis using one way analysis of variance (continuous data) or $\chi^{2}$ (categorical data) to identify other factors, which may have influenced survival to hospital discharge. Logistic regression analysis of these factors was performed to identify those that were significantly associated with survival. All $\mathrm{p}$ values are for two tailed tests.

\section{RESULTS}

Between May 2000 and September 2001, 60 patients were enrolled into the study representing about one in four patients who were eligible (fig 1). This comparatively low rate of recruitment occurred despite 24 hour research registrar cover for the project and illustrates some of the difficulties with emergency medicine research. Baseline characteristics of those patients included in the study and eligible patients not included are shown in table 1 . There was no statistical difference between the groups in any of the parameters shown, including time of arrival in the department, confirming that the patients randomised were a representative group.

The three study groups were not significantly different in any of the baseline characteristics, which are shown in table 2. The doses of pharmacological agents used during the first two hours of the study are shown in table 3. There was no significant difference between the groups in the dose of any of these agents.

\section{Outcome}

Three $(15 \%)$ patients in the control group, seven $(35 \%)$ in the CPAP group, and nine $(45 \%)$ in the bilevel group met the 


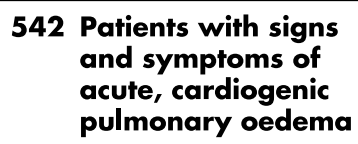

\section{Not eligible}

187 arterial $\mathrm{pH}>7.35$

52 respiratory rate $<23 \mathrm{bpm}$

16 were feverish (temp $>38^{\circ} \mathrm{C}$ )

15 were comatose (scoring $\mathrm{P}$ or $\mathrm{U}$ on AVPU scale)

14 were hypotensive (systolic BP $<90 \mathrm{~mm} \mathrm{Hg}$ )

14 received immediate thrombolysis for $\mathrm{Ml}$

8 needed dialysis

\section{Not randomised}

102 researcher not contacted

33 unable to obtain consent

22 improved with initial treatment and no longer fitted entry criteria

19 inconvenient for researcher

60 Randomised

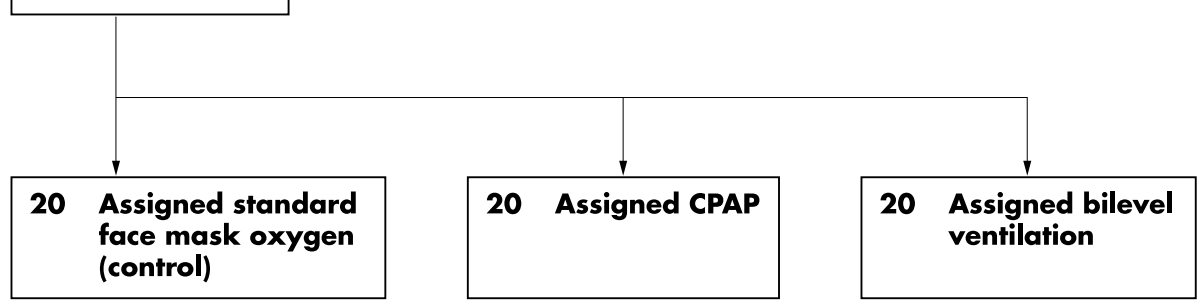

Table 1 Baseline characteristics of randomised and not randomised patients

\begin{tabular}{|c|c|c|}
\hline & \multicolumn{2}{|l|}{ Patient group } \\
\hline & Randomised $(n=60)$ & Not randomised $(n=176)$ \\
\hline \multicolumn{3}{|l|}{ Demography } \\
\hline Age $(y)^{*}$ & $75.1(10.5)$ & $78.3(9.2)$ \\
\hline Male sex (\%) & 38.3 & 36.9 \\
\hline \multicolumn{3}{|l|}{ Time of arrival } \\
\hline 0000-0759 (\%) & 38.3 & 43.9 \\
\hline 0800-1559 (\%) & 31.7 & 33.0 \\
\hline $1600-2359(\%)$ & 30.0 & 23.1 \\
\hline \multicolumn{3}{|l|}{ Physiology on arrival } \\
\hline Heart rate $(\mathrm{bpm})^{*}$ & $111(21)$ & $112(23)$ \\
\hline Respiratory rate $(\mathrm{bpm})^{*}$ & $35(7)$ & $32(6)$ \\
\hline Systolic blood pressure $\left(\mathrm{mm} \mathrm{Hg}^{*}\right.$ & $166(39)$ & $165(36)$ \\
\hline Diastolic blood pressure $(\mathrm{mm} \mathrm{Hg})^{*}$ & $92(21)$ & $87(22)$ \\
\hline Arterial blood $\mathrm{H}^{+}$ion concentration $(\mathrm{nmol} / \mathrm{l})^{*}$ & $64.80(13.89)$ & $61.61(15.01)$ \\
\hline Arterial blood $\mathrm{pH}^{*}$ & $7.197(0.09)$ & $7.221(0.09)$ \\
\hline Arterial blood $\mathrm{pO}_{2}(\mathrm{kPA})^{*}$ & $13.23(7.42)$ & $13.07(7.08)$ \\
\hline Arterial blood $\mathrm{pCO}_{2}(\mathrm{kPA})^{*}$ & $8.22(2.47)$ & $8.07(2.57)$ \\
\hline Arterial blood oxygen saturation (\%)* & $89.9(10.4)$ & $91.8(7.4)$ \\
\hline \multicolumn{3}{|l|}{ History (number (\%) of patients) } \\
\hline Heart failure & $24(40)$ & $49(28)$ \\
\hline Ischaemic heart disease & $32(53)$ & 77 (44) \\
\hline Diabetes mellitus & $15(25)$ & $46(26)$ \\
\hline Hypertension & $22(37)$ & $32(18)$ \\
\hline Chronic obstructive pulmonary disease & $16(27)$ & $39(22)$ \\
\hline
\end{tabular}


Table 2 Baseline characteristics of the three treatment groups

\begin{tabular}{|c|c|c|c|}
\hline & \multicolumn{3}{|l|}{ Treatment arm } \\
\hline & Control $(n=20)$ & CPAP $(n=20)$ & Bilevel $(n=20)$ \\
\hline \multicolumn{4}{|l|}{ Demography } \\
\hline Age $(y)^{*}$ & $74.6(11.1)$ & $74.9(12.2)$ & $76.0(8.4)$ \\
\hline Male sex $(\%)$ & $9(45)$ & $8(40)$ & $6(30)$ \\
\hline \multicolumn{4}{|l|}{ Physiology on arrival } \\
\hline Heart rate $(\mathrm{bpm})^{*}$ & $110(23)$ & $113(18)$ & $110(23)$ \\
\hline Respiratory rate $(\mathrm{bpm})^{*}$ & $36(7)$ & $35(6)$ & $35(8)$ \\
\hline Systolic blood pressure $(\mathrm{mm} \mathrm{Hg})^{*}$ & $165(42)$ & $166(42)$ & $166(34)$ \\
\hline Diastolic blood pressure $(\mathrm{mm} \mathrm{Hg})^{*}$ & $92(21)$ & $93(25)$ & $92(16)$ \\
\hline Arterial blood $\mathrm{H}^{+}$ion concentration $(\mathrm{nmol} / \mathrm{l})^{*}$ & $63.47(11.33)$ & $68.76(17.86)$ & $62.16(11.20)$ \\
\hline Arterial blood $\mathrm{pH}^{*}$ & $7.204(0.078)$ & $7.175(0.105)$ & $7.212(0.074)$ \\
\hline Arterial blood $\mathrm{pO}_{2}(\mathrm{kPA})^{*}$ & $13.45(7.23)$ & $13.75(9.19)$ & $12.49(5.75)$ \\
\hline Arterial blood $\mathrm{pCO}_{2}(\mathrm{kPA})^{*}$ & $7.44(2.33)$ & $9.21(2.56)$ & $8.01(2.28)$ \\
\hline Arterial blood oxygen saturation (\%)* & $91(8)$ & $89(11)$ & $90(12)$ \\
\hline \multicolumn{4}{|l|}{ Past history (number (\%) of patients) } \\
\hline Heart failure & $7(35)$ & $5(25)$ & $12(60)$ \\
\hline Ischaemic heart disease & $12(60)$ & $9(45)$ & $11(55)$ \\
\hline Diabetes mellitus & $5(25)$ & $4(20)$ & $6(30)$ \\
\hline Hypertension & $5(25)$ & $6(30)$ & $11(55)$ \\
\hline Chronic obstructive pulmonary disease & $6(30)$ & $3(15)$ & $7(35)$ \\
\hline
\end{tabular}

criteria for treatment success at two hours $(p=0.116)$. One patient in the control group, four patients in the CPAP group, and one patient in the bilevel group met the criteria for treatment failure and were considered for intubation and mechanical ventilation $(p=0.344)$. However, only two patients were actually intubated (one in the CPAP group and one in the bilevel group). In the other three CPAP patients who reached criteria for treatment failure, one patient continued on CPAP beyond two hours on the admitting ward, one was transferred onto bilevel ventilation and this continued for a short period during admission to the respiratory high dependency unit, and the other was taken off all forms of non-invasive ventilation before admission. The control arm patient reaching criteria for treatment failure did so because of persistent tachypnoea in the first hour of the study period, but did not require ventilatory support and survived to discharge from hospital. All the other patients in the two treatment arms had only two hours of the assigned treatment while in the emergency department.

\section{Physiological measurements}

Table 4 shows physiological measurements during two hour study period. Oxygen saturation was significantly lower in the CPAP group compared with controls at 10 (mean $\mathrm{Spo}_{2}$ $5.9 \%$ lower; $\mathrm{p}=0.02$ ), 20 (mean $\mathrm{SpO}_{2} 5.8 \%$ lower; $\mathrm{p}=0.05$ ), and 30 (mean $\mathrm{SpO}_{2}$ 6.3\% lower; $\mathrm{p}=0.03$ ) minutes after randomisation. There was no statistical difference between the three groups, in any of the other parameters, at any other time point. The respiratory rate fell significantly from baseline (the time of application of the study treatment) by 10 minutes after randomisation in the bilevel group (mean fall of 4.5 breaths per minute by 10 minutes; $p=0.001$ ). However, a significant fall in respiratory rate did not occur until 40 minutes after randomisation in the CPAP group (mean fall of 3.7 breaths per minute by 40 minutes; $\mathrm{p}=0.036$ ) and 50 minutes in the control group (mean fall of 3.6 breaths per minute by 50 minutes; $p=0.016$ ). There were no differences, between the groups, in the rate of change or the percentage change of any of the other physiological or blood gas parameters. The mean total urine output over the two hour study period was $443 \mathrm{ml}$ in the control group, $359 \mathrm{ml}$ in the CPAP group, and $415 \mathrm{ml}$ in the bilevel group $(\mathrm{p}=0.602)$.

Only 33 patients were able to provide useable data on the visual analogue score for breathlessness (15 in the control group, 8 in the CPAP group, and 10 in the bilevel group). Some were too ill to physically complete the task and others were unable to understand what was being asked of them. The use of visual analogue scales in such critically ill patients is, therefore, of dubious value. However, the median (IQR) value fell from $77 \mathrm{~mm} \mathrm{(58-98)} \mathrm{at} \mathrm{baseline} \mathrm{to} 13 \mathrm{~mm} \mathrm{(5-24)}$ at 120 minutes, in the control group. The corresponding figures for CPAP were $91 \mathrm{~mm}$ (59-100) falling to $18 \mathrm{~mm}$ (6-35), and for bilevel $99 \mathrm{~mm}$ (96-100) falling to $12 \mathrm{~mm}$ (9-36). These changes were not significantly different $(\mathrm{p}=0.322$, Kruskal-Wallis test $)$.

Table 3 Pharmacological treatments given to the three treatment groups

\begin{tabular}{|c|c|c|c|}
\hline & \multicolumn{3}{|l|}{ Treatment arm } \\
\hline & Control $(n=20)$ & CPAP $(n=20)$ & Bilevel $(n=20)$ \\
\hline \multicolumn{4}{|c|}{ Median dose (IQR) given in two hour study period (mg) } \\
\hline Frusemide & $90(80$ to 153$)$ & $80(65$ to 128$)$ & $80(80$ to 80$)$ \\
\hline Sublingual suscard buccal & $4.0(0.5$ to 5.0$)$ & $5.0(0.5$ to 5.0$)$ & $1.0(0$ to 5.0$)$ \\
\hline Intravenous glyceryl trinitrate & 2.92 (0 to 6.48$)$ & $2.84(0.71$ to 10.50$)$ & 3.42 (0.95 to 6.69$)$ \\
\hline Total nitrate dose & $5.5(3.4$ to 8.6$)$ & $5.4(2.9$ to 14.6$)$ & $5.1(3.5$ to 7.6$)$ \\
\hline Diamorphine & $1.25(0$ to 3.25$)$ & $1.75(0$ to 2.5$)$ & $2.00(0.25$ to 2.5$)$ \\
\hline \multicolumn{4}{|c|}{ Proportion (\%) of patients receiving } \\
\hline Nebulisers & 60 & 40 & 20 \\
\hline Prehospital sublingual nitrate & 45 & 55 & 35 \\
\hline Intravenous glyceryl trinitrate & 70 & 75 & 85 \\
\hline
\end{tabular}


Table 4 Mean (SD) physiological measurements during the two hour study period

\begin{tabular}{|c|c|c|c|c|c|c|c|c|}
\hline & On arrival & Baseline & 20 minutes & 40 minutes & 60 minutes & 80 minutes & 100 minutes & 120 minutes \\
\hline \multicolumn{9}{|c|}{ Heart rate (bpm) } \\
\hline Control & $110(23)$ & $101(24)$ & $100(24)$ & $98(24)$ & 94 (27) & $90(24)$ & $87(22)$ & $91(21)$ \\
\hline CPAP & $113(18)$ & $104(18)$ & $103(21)$ & $97(24)$ & $97(24)$ & $95(26)$ & $94(24)$ & 91 (23) \\
\hline Bilevel & $110(23)$ & $106(24)$ & $103(32)$ & $96(29)$ & $95(27)$ & $89(25)$ & $93(29)$ & $92(25)$ \\
\hline \multicolumn{9}{|c|}{$\begin{array}{l}\text { Respiratory rate } \\
\text { (bpm) }\end{array}$} \\
\hline Control & $36(7)$ & $30(6)$ & $29(5)$ & $28(7)$ & $26(6)$ & $25(6)$ & $24(7)$ & $24(7)$ \\
\hline CPAP & $35(6)$ & $28(8)$ & $28(8)$ & $23(7)$ & $24(8)$ & $22(7)$ & $21(6)$ & $21(7)$ \\
\hline Bilevel & $35(8)$ & $30(6)$ & $25(8)$ & $24(7)$ & $24(6)$ & $22(7)$ & $20(6)$ & $20(6)$ \\
\hline \multicolumn{9}{|c|}{ Systolic BP (mm Hg) } \\
\hline Control & $165(42)$ & $146(38)$ & $129(32)$ & $124(22)$ & $121(25)$ & 117 (17) & $114(22)$ & $121(17)$ \\
\hline CPAP & $166(42)$ & $164(41)$ & 138 (32) & $128(28)$ & $132(26)$ & 127 (18) & $126(19)$ & $120(21)$ \\
\hline Bilevel & $166(34)$ & $155(33)$ & $136(33)$ & 127 (33) & $127(30)$ & $125(27)$ & $128(25)$ & $114(33)$ \\
\hline \multicolumn{9}{|c|}{ Diastolic BP $(\mathrm{mm} \mathrm{Hg})$} \\
\hline Control & $92(21)$ & $78(21)$ & $67(17)$ & $65(14)$ & $64(11)$ & $63(8)$ & $58(14)$ & $66(14)$ \\
\hline CPAP & $93(25)$ & $89(22)$ & $74(16)$ & $71(16)$ & $73(17)$ & 70 (15) & $67(11)$ & $61(11)$ \\
\hline Bilevel & $92(16)$ & $81(17)$ & 74 (19) & 67 (19) & 67 (17) & $65(13)$ & 64 (13) & $64(16)$ \\
\hline \multicolumn{9}{|c|}{$\begin{array}{l}\text { Arterial } \mathrm{H}^{+} \text {ion } \\
\text { concentration } \\
\text { (nmol/l) }\end{array}$} \\
\hline Control & $63.47(11.33)$ & & & & $46.19(12.27)$ & & & $45.29(4.43)$ \\
\hline CPAP & $68.76(17.86)$ & & & & $53.08(12.70)$ & & & $48.84(9.85)$ \\
\hline Bilevel & $62.16(11.20)$ & & & & $50.67(12.75)$ & & & $45.96(10.05)$ \\
\hline \multicolumn{9}{|c|}{ Arterial pH } \\
\hline Control & $7.20(0.08)$ & & & & $7.32(0.05)$ & & & $7.35(0.04)$ \\
\hline CPAP & $7.18(0.11)$ & & & & $7.29(0.10)$ & & & $7.32(0.08)$ \\
\hline \multirow{2}{*}{\multicolumn{9}{|c|}{$\mathrm{pO}_{2}$ (kPA) }} \\
\hline & & & & & & & & \\
\hline Control & $13.45(7.23)$ & & & & $12.83(4.93)$ & & & $13.27(4.96)$ \\
\hline CPAP & 13.75 (9.19) & & & & $9.02(2.41)$ & & & $11.16(3.86)$ \\
\hline Bilevel & 12.49 (5.75) & & & & $11.19(4.47)$ & & & $12.77(6.23)$ \\
\hline \multicolumn{9}{|c|}{$\mathrm{PCO}_{2}$ (kPA) } \\
\hline Control & $7.44(2.33)$ & & & & $5.99(1.47)$ & & & $5.74(1.30)$ \\
\hline CPAP & $9.21(2.56)$ & & & & $7.39(2.76)$ & & & $6.76(1.95)$ \\
\hline Bilevel & $8.01(2.28)$ & & & & $6.67(2.28)$ & & & $6.00(1.60)$ \\
\hline \multicolumn{9}{|c|}{$\mathrm{SaO}_{2}(\%)$} \\
\hline Control & $91.3(8.2)$ & & & & $95.0(3.7)$ & & & $96.1(3.3)$ \\
\hline CPAP & $88.8(10.9)$ & & & & $89.9(5.7)$ & & & $93.6(5.9)$ \\
\hline Bilevel & 89.7 (12.1) & & & & $92.3(7.0)$ & & & $94.9(4.7)$ \\
\hline
\end{tabular}

\section{Tolerance and adverse effects}

Three patients in the CPAP group and two patients in the bilevel group could not tolerate assisted ventilation. One patient in each of the two intervention arms developed minor facial erythema as a result of the face mask. Two patients in the control group and one in the CPAP group vomited during the study period.

\section{Myocardial infarction rate and survival}

There was no significant difference in the myocardial infarction rate between the three groups (control 6, CPAP 3 , bilevel group $9, p=0.117$ ). There was a non-significant trend towards higher median peak creatine kinase in the bilevel group (268 IU/l, IQR 135 to 517 IU/1), compared with control (147 IU/l, IQR 74 to $333 \mathrm{IU} / \mathrm{l}$ ) and CPAP (134 IU/l, IQR 98 to $253 \mathrm{IU} / \mathrm{l})$ patients ( $\mathrm{p}=0.159$, Kruskal-Wallis test).

Fourteen $(70 \%)$ of the control group patients survived to hospital discharge, compared with $20(100 \%)$ in the CPAP group and $15(75 \%)$ in the bilevel group $(\mathrm{p}=0.029$; Fisher's test). Patients randomised to CPAP were significantly more likely to survive to hospital discharge than those in either of the other groups.

Compared with patients who did not survive to hospital discharge, patients who did had higher arrival systolic blood pressure (171 mm $\mathrm{Hg}$ (38) versus $142 \mathrm{~mm} \mathrm{Hg} \mathrm{(31);}$ $\mathrm{p}=0.021)$, were given a higher median total nitrate dose during the two hour study period $(5.9 \mathrm{mgs}$ versus $4.1 \mathrm{mg}$; $\mathrm{p}=0.042$ ) and were more likely to have been given sublingual nitrates by ambulance personnel before arrival at the hospital ( $53 \%$ versus $9 \%$; $p=0.016)$. However, when the three factors identified above and treatment arm were entered into a logistic regression model, no one factor remained a significant predictor of survival to hospital discharge.

Among the six patients in the control group who died before hospital discharge three died within a week of admission (at two, two, and four days respectively) and three died later (at 16, 26, and 41 days). In the bilevel group four died within a week of admission (at one, one, four, and six days respectively) and only one patient died later (at 21 days). Thus, seven day survival in the control group was 17 of $20(85 \%)$ compared with 20 of $20(100 \%)$ in the CPAP group and 16 of $20(80 \%)$ in the bilevel group. This difference did not reach significance ( $p=0.144$; Fisher's test).

Twelve of the 27 patients who received sublingual nitrates before their arrival in the emergency department reached the criteria for treatment success at two hours, compared with 7 of the 33 patients who had not received this treatment $\left(p=0.054 ; \chi^{2}\right.$ test $)$. Also, 1 of the 27 patients who received prehospital sublingual nitrates reached the criteria for treatment failure at two hours, compared with 5 of the 33 patients who had not received this treatment $(p=0.209$; Fisher's test). However, all 27 patients who had been given sublingual nitrates by ambulance personnel before their arrival at the hospital survived seven days, compared with only 26 of $33(79 \%)$ patients who had not received this treatment $(\mathrm{p}=0.013$; Fisher's test $)$.

\section{DISCUSSION}

This study represents the largest study to date directly comparing CPAP with bilevel ventilation and conventional 
therapy in the treatment of patients with CPO and is the first to characterise a UK population of patients presenting as an emergency with CPO. In this study, we have shown that patients with acidotic, acute $\mathrm{CPO}$, presenting to the emergency department are more likely to survive to hospital discharge if treated early with CPAP and conventional therapy rather than with bilevel ventilation and conventional therapy or with conventional therapy alone. This is the first study, to our knowledge, to show a definite short term survival benefit with CPAP, although other studies do show a trend towards improved survival. ${ }^{\text {8-10 } 12}$ Pooled data from such studies have also suggested improved survival with CPAP. ${ }^{22}$ As our patients were admitted to a variety of different medical wards and had a variety of comorbidities, it is possible that factors beyond our control (for example, level of clinical surveillance, types of drug regimens used, etc) may have contributed to this mortality difference. However, such variation in subsequent treatments should have applied equally to patients in all three groups. Changing the outcome to seven day survival eliminates the statistical significance of the result. However, this latter observation may simply be the result of the small numbers of patients involved.

We described a higher proportion of patients reaching treatment success in the bilevel arm and a faster rate of improvement from baseline in terms of respiratory rate. However, survival in the bilevel group was no different to that of controls.

Earlier studies, comparing the use of CPAP with standard oxygen therapy in patients with CPO, have also noted short term physiological improvements but no benefit in terms of survival. Bersten et al ${ }^{7}$ noted significant reductions in both respiratory rate and $\mathrm{pCO}_{2}$ after 30 minutes with CPAP but the mortality in this group was $10 \%$ compared with $20 \%$ in controls, a non-significant difference. In the study by Lin et $a l^{9}$ the alveolar-arterial oxygen tension gradient was significantly reduced after three hours of CPAP therapy compared with oxygen alone, but hospital mortality was similar in both groups, being $8 \%$ in those treated with CPAP and $12 \%$ in the control group. Declaux et al ${ }^{11}$ studied patients with non-hypercapnic respiratory failure, although most of these did not have CPO, and noted improvements in oxygenation and respiratory rate at one hour in patients treated with CPAP compared with those treated with oxygen alone. However, intubation rates were not affected and mortality remained high at $30 \%$ in both groups.

From all these studies it is questionable whether early physiological improvements are important predictors of mortality. This point is further emphasised by the fact that, in our study, the group with the most disturbed presenting physiology and the higher proportion of patients reaching treatment failure (the CPAP group) were also the group with the best outcome in terms of survival. This cannot be explained by higher intubation rates given that only one patient in the CPAP arm was actually intubated. Our a priori defined surrogate end points of treatment success and failure have thus been shown to be unrelated to final outcome in terms of survival.

Patients in the CPAP arm were more acidotic and had higher levels of $\mathrm{pCO}_{2}$ at baseline, and this may explain why significant physiological improvements were not seen in the CPAP patients when compared with the other two groups, and the comparatively low rate of treatment success in this arm, given that part of our definition included reversal of acidosis.

It is difficult to relate a two hour period of CPAP in the emergency department to mortality several weeks later, particularly with the lack of short term physiological differences. However, short term nitrate treatment also seemed to have an important effect on longer term survival.
We found that nitrate dose and use of prehospital nitrates was associated with survival to discharge in our 60 patient study group, although this effect was not independently significant in a regression model that included the treatment arm and arrival systolic blood pressure (probably because our study was underpowered to detect any difference). The use of prehospital nitrates was also associated with improved seven day survival. Nitrates have confirmed efficacy in patients with acute $\mathrm{CPO},{ }^{23}$ and it does seem likely that nitrates have a significant part to play in reducing mortality in these patients. This is supported by the results of one study, which suggests that high dose nitrates are more efficacious than non-invasive ventilation in the treatment of patients with $\mathrm{CPO}^{14}$

Unlike the study by Mehta et al, ${ }^{13}$ we did not find an increase in myocardial infarction rate in patients treated with bilevel ventilation although there was a trend towards higher median peak creatine kinase in this group. In Mehta's study, the incidence of chest pain on arrival was much higher in the bilevel arm than the CPAP, indicating a possible failure of randomisation rather than a real increase in myocardial infarction associated with bilevel ventilation. Also, in Mehta's study bilevel ventilation was associated with greater falls in blood pressure when compared with CPAP, perhaps helping to explain their higher myocardial infarction rate. No such difference was found in our study.

Two other randomised studies of bilevel ventilation compared with control treatment failed to show any increased risk of myocardial infarction from bilevel ventilation, ${ }^{15} 16$ but in contrast a study comparing high dose isosorbide dinitrate with bilevel ventilation found higher rates of intubation, myocardial infarction and death in the non-invasive ventilation group. ${ }^{14}$ This study, however, was conducted in mobile intensive care units in Israel, and low pressure settings were used in the ventilator arm, limiting its applicability to UK practice.

In our patients, in common with other reports from UK practice, $^{12}{ }^{18}$ there was a very low rate of intubation among patients presenting with acidotic CPO. Our patients did not include those who were comatose on arrival or who were hypotensive, as these patients are not suitable for noninvasive ventilation techniques. There were 29 of these during the study period of which 15 were intubated. However, the intubation rate was only $3.4 \%$ of the 236 eligible patients. The overall intubation rate for the 265 patients with acidotic CPO was therefore $8.7 \%$ yet despite higher intubation rates, results of some studies from other parts of the world show similar mortality rates to our study. The in-hospital mortality rate for all patients entered into the study was $18 \%$. In Rasenen's study $50 \%$ of the control group were intubated but the in-hospital mortality was still 30\% in this group, raising the question of whether intubation was necessary in all these patients. In other studies ${ }^{7}$ intubation rates of around 35\% have been reported in the control groups, with associated mortality of around 10 to $12 \%$, a little lower than in our study. It is probable that intubation and mechanical ventilation is useful in selected patients, but it is by no means clear that it improves outcome in terms of mortality in most of the CPO patients deemed to need invasive ventilatory support. Our data suggest that such high intubation rates are not necessary.

There are data within the literature to support the use of non-invasive ventilation in patients within the emergency department, ${ }^{24}$ but this is the first randomised study to look specifically at its use in acute CPO in this setting. We have confirmed that non-invasive ventilation can be used safely and that there is a low incidence of important side effects. Our study shows a faster resolution of respiratory rate with bilevel ventilation and a trend towards a greater proportion of 
patients reaching treatment success (resolution of acidosis, oxygen saturation above $90 \%$, and respiratory rate 22 breaths per minute or less) at two hours with this modality.

We have shown that that non-invasive ventilation can be used safely in the emergency department, that there is a low incidence of important side effects, and that patients randomised to treatment with CPAP are more likely to survive to hospital discharge but recognise that this finding is difficult to explain given the lack of short term physiological benefit. Most of the randomised studies to date show beneficial results when CPAP is used in patients with CPO. Whether bilevel ventilation confers any additional advantage remains uncertain. Most studies have small numbers of participants, and the possibility of publication or other biases should be considered. There seems to be little doubt that the use of nitrate medication is also a significant factor in patient outcome. A larger study, in which the nitrate dose for all participants is maximised, is now required to find out if positive pressure ventilation really saves lives. The primary end point should be patient survival rather than intubation or short term physiological change.

\section{ACKNOWLEDGEMENTS}

We would like to acknowledge the support of ResMed, Abingdon, UK, who provided the ventilators for use in the study. ResMed had no role in the design of the study, or in the collection, analysis, or interpretation of the data.

\section{Authors' affiliations}

S D Crane, Department of Emergency Medicine, Leeds General Infirmary, UK

M W Elliott, Department of Respiratory Medicine, St James's University Hospital, Leeds, UK

P Gilligan, Department of Emergency Medicine, St James's University Hospital

K Richards, Department of General Medicine, Leeds General Infirmary A J Gray, Department of Emergency Medicine, Edinburgh Royal Infirmary, UK

\section{REFERENCES}

1 Katz JA, Marks JD. Inspiratory work with and without continuous positive airway pressure in patients with acute respiratory failure. Anesthesiology 1985;63:598-607.

2 Naughton MT, Rahman A, Hara K, et al. Effect of continuous positive airway pressure on intrathoracic and left ventricular transmural pressure in patients with congestive heart failure. Circulation 1995;91:1725-31.

3 Lenique $F$, Habis $M$, Lofaso $F$, ef al. Ventilatory and haemodynamic effects of CPAP in left heart failure. Am J Respir Crit Care Med 1997;155:500-5.

4 Baratz DM, Westbrook PR, Shah PK, et al. Effect of nasal CPAP on cardiac output and oxygen delivery in patients with congestive heart failure. Chest 1992;103:1397-401
5 Rasanen J, Heikkila J, Downs J, et al. Continuous positive airway pressure by face mask in acute cardiogenic pulmonary edema. Am J Cardiol 1985;55:296-300.

6 Vaisanen IT, Rasanen J. Continuous positive airway pressure and supplemental oxygen in the treatment of cardiogenic pulmonary edema. Chest 1987;92:481-5.

7 Bersten AD, Holt AW, Vedig AE, et al. Treatment of severe cardiogenic pulmonary edema with continuous positive airway pressure delivered by face mask. N Engl J Med 1991;325:1825-30.

8 Lin M, Chiang HT. The efficacy of early continuous positive airway pressure therapy in patients with acute cardiogenic pulmonary edema. J Formosan Med Assoc 1991;90:736-43.

9 Lin M, Yang YF, Chiang HT, et al. Reappraisal of continuous positive airway pressure therapy in acute cardiogenic pulmonary edema. Chest 1995; 107:1379-86.

10 Takeda S, Nejima J, Takano T, et al. Effect of nasal continuous positive airway pressure on pulmonary edema complicating acute myocardial infarction. Jpn Circ J 1998;62:553-8.

11 Delclaux C, L'Her E, Alberti C, et al. Treatment of acute hypoxemic nonhypercapnic respiratory insufficiency with continuous positive airway pressure delivered by a face mask: a randomised controlled trial. JAMA 2000;284:2352-60.

12 Kelly CA, Newby DE, McDonagh TA, et al. Randomised controlled trial of continuous positive airway pressure and standard oxygen therapy in acute pulmonary oedema: effects on plasma brain natriuretic peptide concentrations. Eur Heart J 2002;23:1379-86.

13 Mehta S, Jay GD, Woolard RH, et al. Randomized, prospective trial of bilevel versus continuous positive airway pressure in acute pulmonary edema. Crit Care Med 1997; 25:620-8.

14 Sharon A, Shpirer I, Kaluski E, et al. High dose intravenous isosorbide dinitrate is safer and better than Bi-PAP ventilation combined with conventional treatment for severe pulmonary edema. J Am Coll Cardiol 2000;36:832-7.

15 Masip J, Betbese AJ, Paez J, et al. Non-invasive pressure support ventilation versus conventional oxygen therapy in acute cardiogenic pulmonary oedema: a randomised trial. Lancet 2000;356:2126-32.

16 Levitt MA. A prospective, randomised trial of BiPAP in severe acute congestive heart failure. J Emerg Med 2001;21:363-9.

17 Pang D, Keenan SP, Cook DJ, et al. The effect of positive airway support on mortality and the need for intubation in cardiogenic pulmonary edema: a systematic review. Chest 1998;114:1185-92.

18 Crane SD. Epidemiology, treatment and outcome of acidotic, acute, cardiogenic pulmonary oedema presenting to an Emergency department. Eur J Emerg Med 2002;9:320-4.

19 Park M, Lorenzi-Filho G, Feltrim Ml, et al. Oxygen therapy, continuous positive airway pressure, or noninvasive bilevel positive pressure ventilation in the treatment of acute cardiogenic pulmonary edema. Arq Bras Cardiol $2001 ; 76: 221-30$.

20 Hotchkiss JR, Marini JJ. Noninvasive ventilation: an emerging supportive technique for the Emergency Department. Ann Emerg Med 1998;32:470-9.

21 Cross AM. Review of the role of non-invasive ventilation in the emergency department. J Accid Emerg Med 2000;17:79-83.

22 Kelly C, Newby DE, Boon NA, et al. Support ventilation versus conventional oxygen. Lancet 2001;357:1126.

23 Cotter G, Metzkor E, Kaluski E, et al. Randomised trial of high-dose isosorbide dinitrate plus low-dose furosemide versus high-dose furosemide plus low-dose isosorbide dinitrate in severe pulmonary oedema. Lancet 1998;351:389-93.

24 Wood KA, Lewis L, Von Harz B, et al. The use of non-invasive positive pressure ventilation in the emergency department; results of a randomised clinical trial. Chest 1998;113:1339-46. 